\title{
ANALISIS HASIL JAHITAN PANTALON DENGAN TEKNIK KONSTRUKSI POLA DI ATAS KAIN PADA WANITA BERTUBUH GEMUK PENDEK DI TANJUNG TAILOR MEDAN
}

\author{
Nur Nahar Hutabarat ${ }^{1)}$, Nurmaya Napitu ${ }^{2)}$ \\ napitunurmaya@gmail.com
}

\begin{abstract}
Abstrak
Penelitian ini bertujuan untuk mengetahui mutu hasil jahitan pantalon dengan teknik konstruksi pola langsung di atas kain pada wanita bertubuh gemuk pendek di Tanjung Tailor Medan. Penelitian ini dilaksanakan pada bulan Februari 2014. Lokasi penelitian di Tanjung Tailor Medan bertempat di Jalan Kalianda No 31 depan Thamrin Plaza. Metode yang digunakan dalam penelitian ini adalah penelitian deskriptif yang bertujuan untuk mendapatkan informasi yang akurat tentang karakter subjek, hal subjek, atau menggambarkan situasi atau frekwensi kejadian sesuatu. Penelitian ini terdiri dari satu variabel. Populasi penelitian ini adalah wanita bertubuh gemuk pendek dengan ukuran lingkar dada $108 \mathrm{~cm}-112 \mathrm{~cm}$, lingkar pinggang $96 \mathrm{~cm}-100 \mathrm{~cm}$, dan lingkar panggul $112 \mathrm{~cm}-116 \mathrm{~cm}$. Subjek penelitian ini wanita dengan ukuran lingkar dada $108 \mathrm{~cm}-112 \mathrm{~cm}$, lingkar pinggang $96 \mathrm{~cm}-100 \mathrm{~cm}$, dan lingkar panggul $112 \mathrm{~cm}-116 \mathrm{~cm}$ dan tinggi tubuh dibawah rata-rata yaitu $150-160 \mathrm{~cm}$. Objek penelitian adalah 10 hasil jahitan pantalon dengan teknik konstruksi pola di atas kain pada wanita bertubuh gemuk pendek di Tanjung Tailor Medan. Teknik pengumpulan data menggunakan lembar observasi/pengamatan sebanyak lima orang pengamat yang terdiri dari 3 dosen PKK Tata Busana dan 2 orang ahli dibidang pantalon. Untuk menjaring kesepakatan hasil pengamatan dari setiap pengamat digunakan uji kesepakatan dengan menggunakan Analisis Varians Satu Jalur.
\end{abstract}

Berdasarkan hasil perhitungan penilaian pengamatan ditemukan bahwa tidak ada perbedaan yang berarti antara hasil pengamatan dari kelima orang observer (pengamat) atau dapat diartikan bahwa butir-butir komponen hasil jahitan pantalon dengan teknik konstruksi pola di atas kain pada wanita bertubuh gemuk pendek dimana $\mathrm{F}_{0}<\mathrm{F}_{\text {tabel }}(1,43<5,19)$. Dalam penelitian ini menggunakan rumus persentase. Berdasarkan hasil penelitian menunjukkan bahwa $70 \%$ hasil jahitan pantalon dengan teknik konstruksi pola di atas kain pada wanita bertubuh gemuk pendek di tanjung tailor medan baik dengan nilai tertinggi 96,65 dan nilai terendah 79,28. Nilai rata-rata (Mean) sebesar 84,37 dan standar deviasi 5,409. Untuk setiap indikator, indikator yang memiliki presentase tertinggi adalah pada kebersihan hasil pantalon dengan persentase $86 \%$ dan indikator terendah adalah pada penampilan pantalon pada bagian panggul dengan presentase $26 \%$. Hasil nilai rata-rata penilaian pengamat perindikator bahwa indikator yang tertinggi terdapat pada indikator kerapian hasil pantalon dengan skor rata-rata 3,9 sedangkan nilai indikator terendah terdapat pada indikator penampilan pantalon pada bagian panggul dengan skor rata-rata 2,9 .

Kata kunci : Hasil jahitan pantalon, teknik konstruksi pola di atas kain, wanita bertubuh gemuk pendek.

This study aims to determine the quality of stitching trousers with construction techniques directly on the fabric pattern on the short fat woman in Tanjung Medan Tailor. This research was conducted in February 2014. Location of the study in Cape Tailor Field located at No. 31 Jalan Kalianda front Thamrin Plaza . The method used in this research is descriptive research that aims to obtain accurate information about the character of the subject, the subject matter, or describe a situation or the frequency of occurrence of something. The study consisted of a single variable. The study population was a short fat woman with a bust size $108 \mathrm{~cm}-112$ $\mathrm{cm}$, waist circumference $96 \mathrm{~cm}-100 \mathrm{~cm}$, and hip circumference $112 \mathrm{~cm}-116 \mathrm{~cm}$. Subjects of this study of women with chest circumference $108 \mathrm{~cm}-112 \mathrm{~cm}$, waist circumference $96 \mathrm{~cm}-100 \mathrm{~cm}$, and hip

Analisis Hasil Jahitan Pantalondengan Teknik Konstruksi Pola Di Atas -113

Kain Pada Wanita Bertubuh Gemuk Pendek Di Tanjung Tailor Medan Nur Nahar Hutabarat, Nurmaya Napitu 
circumference $112 \mathrm{~cm}-116 \mathrm{~cm}$ and height of the body is below the average is $150-160 \mathrm{~cm}$. The object of research is the result of 10 stitches trousers with construction engineering pattern on the fabric on the short fat woman in Tanjung Medan Tailor . Data collection techniques using the observation sheet / observation five observers consisting of 3 professors PKK dressmaking and 2 experts in pantaloons . To capture the observed agreement of each observer used test agreement using Analysis of Variance One Line .

Based on calculations observation assessment found that there was no significant difference between the observations of the five observers ( observer ) or can be interpreted that the grain yield components trousers with stitching construction technique on the fabric pattern on the short fat woman where F0 < F table $(1.43<$ 5.19 ). In this study using a percentage formula. Based on the results of the study showed that $70 \%$ of the construction techniques stitching trousers with a pattern on the fabric on the short fat woman in cape tailor a good field with the highest value of 96.65 and a low of 79.28. The average value ( mean ) of 84.37 and a standard deviation of 5.409. For each indicator, the indicator has the highest percentage was the cleanliness of the results of trousers with a percentage of $86 \%$ and the lowest indicator is the appearance of trousers in the pelvis with a percentage of $26 \%$. The results of the average value of the observer ratings perindikator that contained the highest indicator in the indicator results neatness trousers with an average score of 3.9 , while the value of the lowest indicators of performance indicators contained in the trousers in the pelvis with an average score of 2.9 .

Keywords : Results trousers with stitching construction technique on the fabric pattern on the fat woman.

\section{Pendahuluan}

Busana merupakan kebutuhan primer bagi manusia, di samping kebutuhan pokok lainnya. Pada awalnya pemakaian busana hanya berfungsi untuk melindungi tubuh dari pengaruh luar, seperti udara dingin dan sinar matahari. Namun seiring dengan perkembangan peradaban manusia, busana sudah memiliki fungsi yang kompleks yakni untuk memperindah diri sehingga menambah rasa percaya diri bagi yang memakainnya. Sesuai perkembangan dunia fashion saat ini pembuatan busana sebaiknya diwujudkan dengan desain yang menarik, selain itu salah satu hal yang menjadi pertimbangan yaitu dilihat dari segi fungsional berupa keluasan dalam bergerak yang disesuaikan dengan kesempatan si pemakai, usia si pemakai dan untuk pembuatan busana ada baiknya juga disesuaikan dengan estetika berbusana yaitu berbusana yang serasi sesuai dengan bentuk tubuh seseorang. Menurut Riyanto (2005) berbusana yang indah dan serasi yang merupakan nilai-nilai estetika berarti harus dapat memilih model, warna dan corak, tekstur yang sesuai dengan si pemakai. Disamping itu busana juga dapat menutupi kekurangan tubuh si pemakai agar tampil lebih cantik dan menarik. Poespo (2004) model busana yang selalu berubah dari tahun ke tahun serta kesadaran akan pentingnya mode melibatkan pengenalan tentang istilah-istilah busana dan bagian-bagian busana. Beragamnya busana wanita satu diantaranya adalah pantalon atau celana panjang. Pantalon pada mulanya merupakan pakaian pria, namun saat ini pantalon adalah salah satu busana yang diminati oleh kaum wanita terutama wanita yang bekerja. Pantalon adalah pakaian luar untuk menutupi badan dari pinggang sampai mata kaki, yang mana pada bagian kaki dipisahkan antara kaki kiri dan kaki kanan (Poespo, 2000). Menurut Widiarti (2006) bahwa pantalon merupakan paduan yang tepat bagi wanita aktif, selain modis dan selalu trendi, pantalon atau celana panjang juga aman membungkus tungkai hingga mata kaki.

Hal senada diungkapkan Halimah (2007) berpendapat bahwa pantalon dapat dijadikan alternatif berbusana ke kantor. Selain membuat bergerak lebih leluasa ketika beraktivitas juga dapat membuat kaki terkesan lebih jenjang. Lebih lanjut Widiarti (2006) mengemukakan bahwa dengan menggunakan pantalon maka akan terasa lebih nyaman, baik pada saat duduk maupun bergerak. Agar mencapai penampilan berbusana serasi yang dapat menutupi kekurangan tubuh juga akan menambah keindahan si pemakai, maka diperlukan pemilihan pantalon yang sesuai dengan bentuk tubuh seseorang.

Halimah (2007) berpendapat bahwa ada beberapa macam bentuk tubuh berdasarkan perbandingan tinggi dan berat badan yaitu bentuk tubuh ideal, kurus, tinggi, kurus pendek, besar badan atas, besar badan bawah, gemuk 
tinggi dan gemuk pendek. Seseorang yang menggeluti dibidang busana sebaiknya mampu menguasai keseluruhan rangkaian dalam pembuatan busana dan dapat memproduksi busana dengan hasil yang baik dan sesuai dengan ukuran si pemakai. Pantalon yang baik dalam arti pas dan enak dipakai, tidaklah diperoleh dengan mudah khususnya dalam pembuatan pantalon untuk wanita bertubuh gemuk.

Menurut Muliawan (2005) busana pada bentuk tubuh gemuk sering terlihat kerutan, tarikan, lipatan pada bagian perut atau sempit yang semestinya tidak ada. Sehingga kesan yang ditimbulkan tidak enak di pandang mata. Terutama wanita dengan postur tubuh pendek gemuk, yang memiliki ciri-ciri antara lain tinggi tubuh dibawah rata-rata $(<160 \mathrm{~cm})$, berat badan lebih dari berat ideal (e-dukasi.net, 2010).

Maka untuk menghasilkan pantalon yang baik pada wanita bertubuh gemuk diperlukan pengetahuan dan keterampilan khusus bagaimana cara pengambilan ukuran, pemilihan bahan, pembuatan pola, teknik cutting hingga finishing.

Berdasarkan wawancara kepada pimpinan Tanjung Tailor Medan Bapak H. Wirman Tanjung, banyak pelanggan wanita yang menjahitkan pantalon di Tanjung Tailor Medan dan menurut Bapak H. Wirman Tanjung mereka sudah berulang kali menjadi pelanggan tetap. Namun dari pengamatan penulis para wanita yang menjadi pelanggan tersebut, hasil jahitan pantalon yang mereka gunakan belum maksimal hasilnya terutama untuk wanita yang berbadan gemuk pendek masih ditemukan masalah misalnya pesak yang tertarik kebelakang, kerutan pada selangkangan, pahanya terlalu sempit dan pipa celana seperti bergelombang. Oleh sebab itu penulis tertarik untuk mengangkat judul dengan menggunakan teknik konstruksi pola di atas kain di Tanjung Tailor Medan, dan supaya mahasiswa Unimed Jurusan Tata Busana khususnya mata kuliah busana pria nantinya dapat menerapkannya.

Berdasarkan hasil observasi penulis bahwa pada umumnya tailor menggunakan teknik konstruksi pola di atas kain, adapun alasan mereka menggunakan teknik konstruksi pola di atas kain yaitu pembuatannya lebih praktis, efisien dan hemat biaya. Salah satunya Tanjung Tailor Medan.

Tanjung Tailor Medan adalah salah satu usaha dalam bidang produksi busana, dimana sudah terkenal di kota Medan oleh kalangan masyarakat dan instansi-instansi pemerintah maupun swasta. Penulis berasumsi penjahit yang terkenal dianggap mampu dan dapat menghasilkan pantalon yang baik sesuai dengan ukuran si pemakainya. Hal ini karena pengalaman penjahit tersebut selama bertahun tahun dalam mengelola usahanya.

Cara pembuatan pola langsung di atas kain atau bahan pada Tanjung Tailor Medan secara ringkas yaitu: 1). Bahan yang akan di gunting dibalik menjadi bagian buruk 2). Membuat garis penolong untuk mengetahui jatuhnya lingkar pesak, lingkar panggul, lingkar lutut, lingkar kaki dan garis tengah 3). Membuat pola bagian muka sesuai ukuran yang telah ditentukan 4). Pola di gunting 5). Pembuatan pola bagian belakang, pola bagian muka di tempelkan sebagai patokan untuk pembuatan pola bagian belakang yang pada bagian lingkar paha, lingkar panggul, lingkat pinggang, lingkar lutut dan lingkar kaki ada penambahan ukuran 6). Pola bagian belakang di gunting. Untuk menandai garis pola, tidak menggunakan rader tetapi cukup dengan menggunakan kapur jahit yang disebut dengan pemindahan garis. Oleh sebab itu penulis merasa tertarik untuk menganalisis hasil jahitan pantalon dengan teknik konstruksi pola di atas untuk wanita bertubuh gemuk pendek di Tanjung Tailor Medan.

Oleh karena itu berdasarkan pernyataan diatas, maka peneliti ingin melakukan penelitian tentang "Analisis Hasil Jahitan Pantalon Dengan Teknik Konstruksi Pola Di Atas Kain Pada Wanita Bertubuh Gemuk Pendek Di Tanjung Tailor Medan”.

\section{Metodologi Penelitian}

Penelitian ini dilaksanakan di Tanjung Tailor Medan yang terletak di Jalan Kalianda No. 31 Medan dan dilaksanakan pada bulan Februari 2014.

Menurut Sudjana (2002) mengatakan populasi merupakan keseluruhan subjek yang akan diteliti. Menurut Sugiono (2011) populasi adalah generalisasi yang terdiri atas objek atau

Analisis Hasil Jahitan Pantalondengan Teknik Konstruksi Pola Di Atas -115

Kain Pada Wanita Bertubuh Gemuk Pendek Di Tanjung Tailor Medan 
subjek yang mempunyai kualitas dan karakteristik tertentu yang ditetapkan oleh peneliti untuk dipelajari kemudian ditarik kesimpulannya. Maka dari kesimpulan diatas populasi penelitian ini adalah wanita bertubuh gemuk pendek. dengan ukuran lingkar dada 108 $\mathrm{cm}-112 \mathrm{~cm}$, lingkar pinggang $96 \mathrm{~cm}-100 \mathrm{~cm}$ dan lingkar panggul $112 \mathrm{~cm}-116 \mathrm{~cm}$.

Menurut Sugiyono (2011) sampel adalah bagian dari jumlah dan karakteristik yang dimiliki oleh populasi tersebut. Bila populasi besar, dan peneliti tidak mungkin mempelajari semua yang ada dipopulasi, misalnya karena keterbatasan dana, tenaga dan waktu maka peneliti dapat menggunakan sampel diambil dari populasi itu. Apa yang dipelajari dari sampel itu kesimpulannya akan dapat diberlakukan untuk populasi. Untuk itu sampel yang diambil dari populasi harus betul - betul representatif. Menurut Nyoman (2012) menentukan jumlah sampel sangat penting agar mendapatkan perhitungan yang lebih akurat. Pengambilan jumlah sampel berdasarkan kuota (jatah). Hal ini mempertimbangkan keterbatasan dana, tenaga dan waktu maka peneliti dapat menggunakan sampel yang diambil dari populasi itu, maka diambil kuota sebanyak 10 wanita bertubuh gemuk sesuai dengan kriteria ukuran yang telah ditentukan oleh peneliti. Teknik pengambilan sampel dilakukan dengan teknik snowball, menurut Risa (2012) sampling snowball merupakan teknik penentuan sampel yang awalnya berjumlah kecil, kemudian berkembang semakin banyak. Orang yang menjadi sampel pertama diminta memilih atau menunjuk orang lain untuk dijadikan sampel lagi, begitu seterusnya sampai jumlahnya lebih banyak. Dari kesimpulan diatas, maka subjek penelitian adalah 10 wanita bertubuh gemuk pendek dengan ukuran lingkar dada $108 \mathrm{~cm}-$ $112 \mathrm{~cm}$, lingkar pinggang $96 \mathrm{~cm}-100 \mathrm{~cm}$ dan lingkar panggul $112 \mathrm{~cm}-116 \mathrm{~cm}$ dan tinggi tubuh dibawah rata-rata yaitu $150-160 \mathrm{~cm}$, dengan objek penelitian adalah 10 hasil jahitan pantalon dengan teknik konstruksi pola di atas kain pada wanita bertubuh gemuk pendek di Tanjung Tailor Medan.

Metode yang digunakan dalam penelitian ini adalah metode deskriptif yaitu suatu cara atau teknik yang menggunakan fakta yang jelas tentang gejala - gejala yang ada pada suatu objek penelitian.
Menurut Sugiono (2011) mengemukakan bahwa permasalahan deskriptif adalah suatu permasalahan yang berkenaan dengan pertanyaan terhadap keberadaan variabel baik hanya pada satu variabel atau lebih. Arikunto (2010) bahwa metode deskriptif digunakan untuk upaya memecahkan masalah yang dihadapi pada situasi sekarang, dilakukan dengan menempuh langkah - langkah pengumpulan klasifikasi dan analisis atau pengolahan data memberi penjabaran tentang suatu objek dalam suatu deskriptif situasi.

Instrumen penelitian yang digunakan dalam penelitian ini adalah lembar observasi, kriteria yang berisi butir - butir pernyataan yang berkaitan dengan pembuatan pantalon sampai dengan tahap akhir yang dilihat dari bagian muka, samping dan belakang. Dengan lembar kriteria ini akan diperoleh data yang objektif tentang hasil pantalon pada wanita bertubuh gemuk pendek. Pengamatan dilakukan oleh 5 orang obsever (pengamat) yang dianggap ahli pada bidang yang diamati. Pengamat adalah 3 dosen PKK Tata Busana dan 2 orang praktisi bidang pantalon.

Teknik pelaksanaanya hendaknya mengurangi adanya bias kesalahan dengan jalan pengamat tidak boleh bekerjasama dalam menentukan nilai skor dari tiap komponen yang telah tersedia. Penentuan skor dilakukan dengan cara memberi skor $4=$ Sangat baik, skor $3=$ Baik, skor 2 = Cukup dan skor $1=$ Kurang.

Dalam penelitian ini, pengamat atau obsever yang digunakan sebanyak 5 orang pengamat (obsever), dimana kelima obsever yaitu 3 dosen prodi Tata Busana Jurusan PKK yang dianggap memiliki kualitas dibidangnya dan 2 orang praktis dibidang pantalon, untuk menilai apakah kelima pengamat atau obsever yang digunakan untuk mengumpulkan data penilaian memiliki kualifikasi yang sama maka diperlukan uji kesepakatan pada kelima orang pengamat. Sebelum dilakukan pengamat oleh kelima obsever, terlebih dahulu dilakukan uji kesepakatan.

Untuk menjaring kesepakatan hasil pengamatan dari setiap pengamat dalam hasil jahitan pantalon dengan teknik konstruksi pola di atas kain pada wanita bertubuh gemuk pendek di Tanjung Tailor Medan maka digunakan uji kesepakatan dengan 
menggunakan Analisis Varians Satu jalur yang dikemukakan oleh Sudjana (2002).

Hasil Analisis Varians (F reg hitung) dikonsultasikan dengan $\mathrm{F}$ reg tabel dengan taraf signifikan $5 \%$. Bila $\mathrm{F}$ reg hitung < F reg tabel 5 $\%$ maka disimpulkan tidak ada perbedaan hasil penilaian kelima pengamat, sehingga lembar pengamatan dapat digunakan untuk menjaring data penelitian.

Setelah semua data dikumpulkan, maka data tersebut segera ditabulasi dan diolah sesuai dengan tujuan penelitian ini dan selanjutnya dianalisis secara statistik. Dalam hal ini digunakan teknik analisa data sebagai berikut : data dari setiap variabel penelitian dipaparkan dengan menggunakan metode statistik deskriptif , yaitu untuk menentukan harga rata-rata (M) dan simpangan baku / Standar Deviasi.

Membuat Persentase Terhadap Hasil Jahitan Pantalon Pada Wanita Dengan Teknik Konstruksi Pola Di Atas Kain Pada Wanita Bertubuh Gemuk Pendek di Tanjung Tailor Medan $\mathrm{P}=\frac{F}{N} \times 100 \%$ (Sugiono (2011).

Berdasarkan hasil pengumpulan data yang dilakukan pada wanita bertubuh gemuk pendek di Tanjung Tailor Medan tentang hasil jahitan pantalon dengan teknik konstruksi pola langsung di atas kain diketahui bahwa skor tertinggi adalah 96,65 dengan kategori hasil jahitan pantalon dengan teknik konstruksi pola di atas kain pada wanita bertubuh gemuk pendek di Tanjung Tailor Medan sangat baik dan skor terendah 79,28 dengan kategori hasil jahitan pantalon dengan teknik konstruksi pola di atas kain pada wanita bertubuh gemuk pendek di Tanjung Tailor Medan cukup baik. Skor rata-rata (Mean) sebesar 84,37 dengan standar deviasi 5,409. Berikut adalah tabel hasil distribusi frekwensi nilai hasil jahitan pantalon dengan teknik konstruksi pola di atas kain pada wanita bertubuh gemuk pendek di Tanjung Tailor Medan pada penelitian.

Tabel . Deskripsi Data Pengamatan

\begin{tabular}{|c|c|c|c|c|}
\hline No & Interval Kelas & Skor & Frekuensi & $\%$ \\
\hline 1 & $\begin{array}{l}M-3 S D \text { s/d } \\
M-2 S D\end{array}$ & $\begin{array}{l}68,14 \\
\text { s/d } \\
73,55\end{array}$ & 0 & $0 \%$ \\
\hline 2 & $\begin{array}{l}M-2 S D s / d \\
M-1 S D\end{array}$ & $\begin{array}{l}73,55 \\
\text { s/d } \\
78,96\end{array}$ & 0 & $0 \%$ \\
\hline 3 & $\mathrm{M}-1 \mathrm{SD} \mathrm{s} / \mathrm{d}$ & 78,96 & 7 & $70 \%$ \\
\hline
\end{tabular}

\begin{tabular}{|c|c|c|c|c|}
\hline & $\mathrm{M}$ & $\begin{array}{l}\text { s/d } \\
84,37\end{array}$ & & \\
\hline 4 & $\begin{array}{l}M \text { s/d M + 1 } \\
\text { SD }\end{array}$ & $\begin{array}{l}84,37 \\
\text { s/d } \\
89,77\end{array}$ & 1 & $10 \%$ \\
\hline 5 & $\begin{array}{l}M+1 S D s / d \\
M+2 S D\end{array}$ & $\begin{array}{l}89,77 \\
\text { s/d } \\
95,1\end{array}$ & 1 & $10 \%$ \\
\hline 6 & $\begin{array}{l}M+2 S D s / d \\
M+3 S D\end{array}$ & $\begin{array}{l}95,1 \\
\text { s/d } \\
100\end{array}$ & 1 & $10 \%$ \\
\hline
\end{tabular}

Gambar. Histogram Distribusi Frekuensi Nilai Hasil Jahitan Pantalon Menggunakan Teknik Konstruksi Pola Di Atas Kain Pada Wanita Bertubuh Gemuk Pendek Di Tanjung Tailor

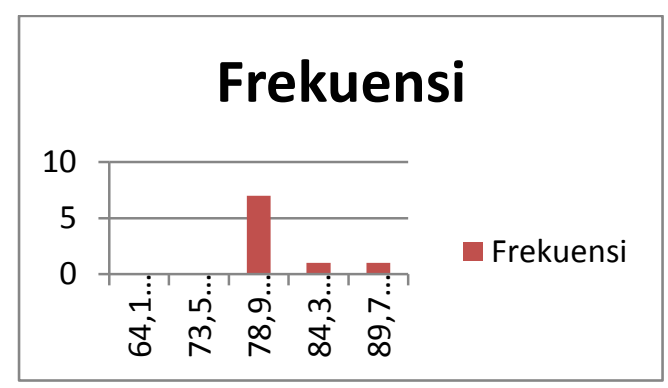

Dari tabel diatas dapat disimpulkan bahwa secara umum subjek penelitian memiliki hasil yang baik dalam melakukan jahitan pantalon dengan teknik konstruksi pola langsung di atas kain pada wanita bertubuh gemuk pendek di Tanjung Tailor Medan dengan persentase sebesar $70 \%$. Uji persyaratan analisa dalam penelitian ini adalah uji kesepakatan pengamat. Uji ini dilakukan untuk mengetahui ada atau tidaknya perbedaan penilaian yang dilakukan oleh pengamat (observer). Setelah dilakukan uji kesepakatan pengamat didapat bahwa $\mathrm{F}_{0}=1,43$ dan $F_{\text {tabel }}=5,19$. Dapat dilihat pada tabel dibawah ini :

Tabel. Hasil Analisis Uji Kesepakatan Pengamat

\begin{tabular}{|c|c|c|c|c|c|}
\hline $\begin{array}{l}\text { Sumber } \\
\text { varians }\end{array}$ & $\mathrm{dk}$ & JK & RJK & $\begin{array}{l}\text { Fh } \\
\text { itu } \\
\text { ng } \\
\text { (F } \\
\text { o) }\end{array}$ & $\begin{array}{c}\text { Ftabel } \\
(5 \%)\end{array}$ \\
\hline $\begin{array}{c}\text { Antar } \\
\text { kelompok }\end{array}$ & 4 & $\begin{array}{c}8872 \\
90.7 \\
9\end{array}$ & $\begin{array}{c}221822 . \\
69\end{array}$ & $\begin{array}{l}1, \\
43\end{array}$ & 5,19 \\
\hline $\begin{array}{c}\text { Dalam } \\
\text { Kelompok }\end{array}$ & 5 & $\begin{array}{c}7731 \\
15.2 \\
3\end{array}$ & $\begin{array}{c}154623 . \\
04\end{array}$ & & \\
\hline Total & 9 & & & & \\
\hline
\end{tabular}

Analisis Hasil Jahitan Pantalondengan Teknik Konstruksi Pola Di Atas -117 Kain Pada Wanita Bertubuh Gemuk Pendek Di Tanjung Tailor Medan Nur Nahar Hutabarat, Nurmaya Napitu 
Untuk menyatakan bahwa tidak ada perbedaan penilaian dari pengamat yang berjumlah 5 orang harus memenuhi criteria $\mathrm{F}_{0}<$ $\mathrm{F}_{\text {tabel }}$. berdasarkan tabel diatas didapat bahwa $\mathrm{F}_{0}$ $=1,43<\mathrm{F}_{\text {tabel }}=5,19$, maka dapat disimpulkan bahwa tidak ada perbedaan penilaian dari kelima pengamat. Setelah uji kesepakatan pengamat telah memenuhi kriteria maka analisis dapat dilanjutkan.

Tabel. Hasil Nilai Rata-rata Penilaian Per Indikator

\begin{tabular}{|c|c|c|}
\hline No. & Indikator & Rata-rata \\
\hline 1 & $\begin{array}{l}\text { Letak pantalon pada ban } \\
\text { pinggang }\end{array}$ & 3,48 \\
\hline 2 & $\begin{array}{l}\text { Penampilan pantalon pada } \\
\text { bagian pinggang }\end{array}$ & 3,48 \\
\hline 3 & $\begin{array}{l}\text { Letak pantalon pada bagian } \\
\text { perut }\end{array}$ & 3,3 \\
\hline 4 & Letak garis pinggang & 3,26 \\
\hline 5 & $\begin{array}{l}\text { Penampilan pantalon pada } \\
\text { bagian panggul }\end{array}$ & 2,9 \\
\hline 6 & Letak garis sisi & 3,4 \\
\hline 7 & Letak tutup tarik pantaloon & 3,4 \\
\hline 8 & Letak saku di sisi pantaloon & 3,3 \\
\hline 9 & $\begin{array}{l}\begin{array}{l}\text { Penampilan bagian pesak } \\
\text { saat duduk }\end{array} \\
\end{array}$ & 3,2 \\
\hline 10 & $\begin{array}{l}\text { Penampilan bagian pesak } \\
\text { saat berdiri }\end{array}$ & 3,3 \\
\hline 11 & $\begin{array}{l}\text { Penampilan bagian pesak } \\
\text { saat melangkah }\end{array}$ & 3,3 \\
\hline 12 & $\begin{array}{l}\text { Penampilan bagian paha saat } \\
\text { duduk }\end{array}$ & 3,1 \\
\hline 13 & $\begin{array}{l}\text { Penampilan bagian paha saat } \\
\text { berdiri }\end{array}$ & 3,1 \\
\hline 14 & $\begin{array}{l}\text { Penampilan bagian paha saat } \\
\text { melangkah }\end{array}$ & 3,3 \\
\hline 15 & $\begin{array}{l}\text { Penampilan jatuhnya } \\
\text { pantalon di kaki }\end{array}$ & 3,4 \\
\hline 16 & $\begin{array}{l}\text { Penampilan panjang } \\
\text { pantalon }\end{array}$ & 3,5 \\
\hline 17 & $\begin{array}{l}\text { Penampilan garis lipatan } \\
\text { pantalon bagian depan }\end{array}$ & 3,4 \\
\hline 18 & $\begin{array}{l}\text { Penampilan garis lipatan } \\
\text { pantalon bagian belakang }\end{array}$ & 3,3 \\
\hline 19 & $\begin{array}{l}\text { Penampilan kupnat bagian } \\
\text { depan dan belakang }\end{array}$ & 3,5 \\
\hline 20 & Kerapian hasil pantalon & 3,9 \\
\hline 21 & Keberhasilan hasil pantalon & 3,8 \\
\hline
\end{tabular}

Berdasarkan tabel diatas didapat bahwa nilai rata-rata dari seluruh sampel paling rendah terdapat pada indikator 5 penampilan pantalon pada bagian panggul dengan skor rata-rata 2,9, sedangkan rata-rata sampel paling tinggi terdapat pada indikator 20 kerapian hasil pantalon dengan skor 3,9

\section{Pembahasan}

1. Hasil pengamatan terhadap indikator letak pantalon pada ban pinggang yang memenuhi kriteria letak pantalon pas pada bagian pinggang pas pada bagian pinggang tepat digaris pinggang dan membentuk pinggang memiliki skor rata-rata 3,48 dengan persentase $60 \%$ dari seluruh sampel penelitian, sedangkan $40 \%$ lainnya hasil pengamatan letak pantalon pada ban pinggang sedikit longgar/sempit pada bagian pinggang dan letak ban pinggang sedikit tidak pas pada bagian pinggang.

2. Hasil pengamatan terhadap indikator penampilan pantalon pada bagian pinggang yang memenuhi kriteria letak pantalon pada ban pinggang pas sesuai dengan badan memiliki skor rata-rata 3,48 dengan persentase $60 \%$ dari seluruh sampel penelitian, sedangkan $40 \%$ lainnya hasil pengamatan penampilan pantalon pada bagian pinggang letak garis sedikit turun/naik dari garis pinggang dan sedikit longgar/sempit.

3. Hasil pengamatan terhadap indikator letak pantalon pada bagian perut yang memenuhi kriteria letak pantalon pada bagian perut pas, rata, tidak longgar dan tidak berkerut memiliki skor rata-rata 3,3 dengan persentase $54 \%$ dari seluruh sampel penelitian, sedangkan $46 \%$ lainnya hasil pantalon pada bagian perut sedikit longgar/sempit dan sedikit tidak rata dan berkerut.

4. Hasil pengamatan terhadap indikator letak garis panggul yang memenuhi kriteria letak garis panggul pas, tepat digaris panggul dan tidak longgar memiliki skor rata-rata 3,26 dengan persentase $46 \%$ dari seluruh sampel penelitian, sedangkan $54 \%$ lainnya hasil letak garis panggul pantalon garis panggul pas tetapi sedikit longgar dan bersayap.

5. Hasil pengamatan terhadap indikator penampilan pantalon pada bagian panggul yang memenuhi kriteria letak pantalon pas pada bagian panggul, rata, letak garis 
panggul lurus tidak bergeser dari sisi panggul memiliki skor rata-rata 2,9 dengan persentase $26 \%$ dari seluruh sampel penelitian, sedangkan $74 \%$ lainnya penampilan pantalon pada bagian panggul sedikit sempit pada bagian panggul letak garis panggul pada sisi sedikit bersayap.

6. Hasil pengamatan terhadap indikator letak garis sisi yang memenuhi kriteria letak jahitan garis sisi pantalon pas, lurus tepat pada garis sisi memiliki skor rata-rata 3,4 dengan persentase $60 \%$ dari seluruh sampel penelitian, sedangkan $40 \%$ lainnya hasil pengamatan letak garis sisi pantalon kurang pas sedikit bergeser kebelakang/kedepan.

7. Hasil pengamatan terhadap indikator letak tutup tarik pantalon yang memenuhi kriteria letak tutup tarik pantalon pas, kedudukan tutup tarik sejajar lurus digaris pesak, rapi dan tidak berkerut memiliki skor rata-rata 3,4 dengan persentase $70 \%$ dari seluruh sampel penelitian, sedangkan $30 \%$ lainnya hasil letak tutup tarik pantalon pas sejajar lurus digaris pesak tetapi sedikit berkerut.

8. Hasil pengamatan terhadap indikator letak saku di sisi pantalon yang memenuhi kriteria letak panjang saku pantalon pas sesuai dengan ukuran, lurus dan tepat dengan garis sisi pantalon memiliki skor rata-rata 3,3 dengan persentase $56 \%$ dari seluruh sampel penelitian, sedangkan $44 \%$ lainnya letak saku di sisi pantalon pas sesuai ukuran tetapi sedikit sempit/longgar dan sedikit bergeser kebelakang/kedepan dari garis sisi pantalon.

9. Hasil pengamatan terhadap indikator penampilan bagian pesak saat duduk yang memenuhi kriteria letak pantalon pada bagian pesak saat duduk pas dan rata memiliki skor rata-rata 3,2 dengan persentase $40 \%$ dari seluruh sampel penelitian, sedangkan $60 \%$ lainnya hasil pantalon pada bagian pesak saat duduk longgar/sempit dan sedikit tertarik.

10. Hasil pengamatan terhadap indikator penampilan bagian pesak saat berdiri yang memenuhi kriteria letak pantalon pada pesak saat berdiri pas dan rata memiliki skor rata-rata 3,3 dengan persentase $40 \%$ dari seluruh sampel penelitian, sedangkan $60 \%$ lainnya hasil pantalon pada bagian pesak saat berdiri sedikit turun, sempit/longgar dan berkerut.
11. Hasil pengamatan terhadap indikator penampilan bagian pesak saat melangkah yang memenuhi kriteria letak pantalon pada bagian pesak saat melangkah pas dan rapi memiliki skor rata-rata 3,3 dengan persentase $48 \%$ dari seluruh sampel penelitian, sedangkan $52 \%$ lainnya hasil pantalon pada bagian pesak saat melangkah longgar/sempit dan sedikit tertarik.

12. Hasil pengamatan terhadap indikator penampilan bagian paha saat duduk yang memenuhi kriteria letak pantalon pada bagian paha saat duduk pas sesuai dengan ukuran lingkar paha memiliki skor rata-rata 3,1 dengan persentase $34 \%$ dari seluruh sampel penelitian, sedangkan $66 \%$ lainnya hasil pantalon pada bagian paha saat duduk sempit/longgar dan berkerut.

13. Hasil pengamatan terhadap indikator penampilan bagian paha saat berdiri yang memenuhi kriteria letak pantalon pada bagian paha saat berdiri pas sesuai dengan ukuran lingkar paha memiliki skor rata-rata 3,1 dengan persentase $32 \%$ dari seluruh sampel penelitian, sedangkan $68 \%$ lainnya hasil pantalon pada bagian paha saat berdiri longgar/sempit.

14. Hasil pengamatan terhadap indikator penampilan bagian paha saat melangkah yang memenuhi kriteria letak pantalon pada bagian paha saat melangkah licin dan rata memiliki skor rata-rata 3,3 dengan persentase $48 \%$ dari seluruh sampel penelitian, sedangkan $52 \%$ lainnya hasil pantalon pada bagian paha saat melangkah sedikit longgar/sempit.

15. Hasil pengamatan terhadap indikator penampilan jatuhnya pantalon dikaki yang memenuhi kriteria letak pantalon di kaki jatuhnya lurus dan tidak melintir memiliki skor rata-rata 3,4 dengan persentase $60 \%$ dari seluruh sampel penelitian, sedangkan $40 \%$ lainnya hasil pantalon di kaki jatuhnya sedikit tidak lurus dan melintir.

16. Hasil pengamatan terhadap indikator penampilan panjang pantalon yang memenuhi kriteria panjang pantalon pas atau garis tepi menyentuh sepatu bagian depan dan jatuh ditumit bagian belakang memiliki skor rata-rata 3,5 dengan persentase $62 \%$ dari seluruh sampel penelitian, sedangkan $38 \%$ lainnya hasil panjang pantalon pas tetapi sedikit berlipat karena panjang pantalon sedikit berlebih. 
17. Hasil pengamatan terhadap indikator penampilan garis lipatan pantalon bagian depan yang memenuhi kriteria letak pantalon pas pada garis lipatan pantalon bagian depan, letak garis lipatan pantalon bagian depan lurus mengikuti arah panjang kain memiliki skor rata-rata 3,4 dengan persentase $48 \%$ dari seluruh sampel penelitian, sedangkan $52 \%$ lainnya penampilan garis lipatan pantalon bagian depan letak pantalon sedikit tidak pas pada garis lipatan pantalon bagian depan, letak garis lipatan pantalon bagian depan lurus mengikuti arah panjang kain.

18. Hasil pengamatan terhadap indikator penampilan garis lipatan pantalon bagian belakang yang memenuhi kriteria letak pantalon pada bagian belakang saat melangkah pas dan rapi memiliki skor ratarata 3,3 dengan persentase $46 \%$ dari seluruh sampel penelitian, sedangkan $54 \%$ lainnya hasil penampilan garis lipatan pantalon bagian belakang letak pantalon sedikit tidak pas pada garis lipatan pantalon bagian belakang dan letak garis lipatan pantalon bagian belakang lurus mengikuti arah panjang kain.

19. Hasil pengamatan terhadap indikator penampilan kupnat bagian depan dan belakang yang memenuhi kriteria letak pantalon pada bagian kupnat bagian depan dan belakang pas dan rapi memiliki skor rata-rata 3,5 dengan persentase $60 \%$ dari seluruh sampel penelitian, sedangkan $40 \%$ lainnya hasil penampilan panjang kupnat pantalon kurang pas, salah satunya sedikit tidak rata.

20. Hasil pengamatan terhadap indikator kerapian hasil pantalon yang memenuhi kriteria letak hasil pantalon tidak ada sisa benang tertinggal dan penyetrikaan pantalon sangat rapi memiliki skor rata-rata 3,9 dengan persentase $84 \%$ dari seluruh sampel penelitian, sedangkan $16 \%$ lainnya hasil pantalon masih terdapat sedikit sisa benang yang tertinggal dan pengepresan atau penyetrikaan pantalon kurang rapi.

21. Hasil pengamatan terhadap indikator kebersihan hasil pantolan yang memenuhi kriteria hasil pantolan sangat bersih secara keseluruhan memiliki skor rata-rata 3,8 dengan persentase $86 \%$ dari seluruh sampel penelitian, sedangkan $14 \%$ lainnya hasil pantalon baik tetapi sedikit kurang bersih secara keseluruhan.

Berdasarkan hasil rata-rata penilaian pengamatan per indikator bahwa nilai indikator yang terendah terdapat pada indikator 5 penampilan pantalon pada bagian panggul dengan skor rata-rata 2,9 sedangkan nilai indikator yang tertinggi terdapat pada indikator 20 kerapian hasil pantalon dengan skor rata-rata 3,9 .

\section{Kesimpulan}

Hasil jahitan pantalon dengan teknik konstruksi pola diatas kain pada wanita bertubuh gemuk pendek di Tanjung Tailor Medan adalah $70 \%$. Hasil jahitan pantalon dengan teknik konstruksi pola di atas kain pada wanita bertubuh gemuk pendek di Tanjung Tailor Medan dengan nilai rata-rata sampel total sebesar 84,37 dan indikator yang memiliki persentase terendah yaitu pada indikator penampilan pantalon pada bagian panggul dengan persentase $26 \%$. Sedangkan indikator yang memiliki nilai tertinggi yaitu pada indikator kebersihan hasil pantalon dengan persentase $86 \%$.

Berdasarkan hasil rata-rata penilaian pengamatan per indikator bahwa nilai indikator yang terendah terdapat pada indikator 5 penampilan pantalon pada bagian panggul dengan skor rata-rata 2,9 sedangkan nilai indikator yang tertinggi terdapat pada indikator 20 kerapian hasil pantalon dengan skor rata-rata 3,9 .

\section{Saran}

1. Penelitian ini hasilnya baik, tetapi perlu dilakukan kajian ulang untuk lebih sempurna lagi, terutama hasil jahitan pantalon pada indikator penampilan bagian panggul pantalon untuk wanita bertubuh gemuk pendek.

2. Sebagai masukan untuk Tanjung Tailor Medan untuk mempertahankan jahitannya tetapi harus memperhatikan atau mengkoreksi pantalon pada bagian panggul. 


\section{DAFTAR PUSTAKA}

Arikunto, Suharsimi. 2010. Prosedur Penelitian. Jakarta : Rineka Cipta.

Asnidar, 2013. Perbedaan Hasil Jahitan Kebaya Modifikasi Yang Menggunakan Pola Sistem Penjahit Wulan Gumilang Dengan Pola Sistem Penjahit Lindawati Pada Wanita Bertubuh Gemuk. Medan : UNIMED.

Dharsono. 2006. Psikologi Pendidikan. Semarang : Pustaka Belajar.

Badudu. 2006. Kamus Besar Bahasa Indonesia. Bandung : Angkasa.

Emir, Threes. 2009. Gaya XL. Jakarta : PT. Gramedia Pustaka Umum.

Ernawati, dkk. 2008. Tata Busana Jilid 2. Jakarta : Direktorat Pembinaan Sekolah Menengah Kejuruan.

Halimah. 2007. Perempuan Membuat Celana Panjang. Jakarta : Suara Merdeka.

Indah. 2012. Kerempeng Mana Keren. Surabaya: Tribun Media.

Isyanti. 2008. 101 Cara Tepat Berpakaian Menurut Bentuk Tubuh. Jakarta : Gramedia Pustaka Umum.

Kefgen, Mary and Fhylis. 2006. Touch Speth Individuality in Clothing Selection and Personal Apperance, A Guide for Costumer. New York : Macmilan Publishing.

Muliawan, Porrie. 2005. Konstruksi Pola Busana Wanita. Jakarta : BPK Gunung Mulia.

Navita. 2013. Kursus Jahit Yogya. http://navita.kususyogya.blogspot.com/ 2013/08/pola-kecil.html, diakses tanggal 4 Januari 2014.

Nyoman. 2012. Metode Penelitian. Yogyakarta : Andi.

Pratiwi, Djati. 2007. Pola Dasar dan Pecah Pola. Yogyakarta : Kanisius.
Poespo, Goet. 2000. Aneka Celana (Pants). Yogyakarta : Kanisius.

2006. Teknik Menggambar Mode Busana. Yogyakarta : Kanisius.

2004. Busana Wanita. Jakarta : BPK Gunung Mulia.

Riduan. 2004. Belajar Muda, Penelitian Untuk Guru, Karyawan dan Peneliti Pemula. Bandung : CV. Alfabeta.

Rita. 2008. 17 Alternatif Untuk Langsing. Jakarta : Niaga Swadaya.

Risa. 2012. Populasi Dan Sampel. Risawida.blogspot.com/2012/11 popula si-dan-sampel.html?m=1, diakses tanggal 3 Januari 2014.

Riyanto, A, Arifah. 2005. Teori Busana. Bandung : Yapemdo.

Sari, Sekar. 2012. Rahasia Cepat Membuat \& Mendesain Baju Sendiri. Jakarta : Dunia Kreasi

Sudiono, Anas. 2008. Pengantar Evaluasi Pendidikan. Jakarta : Pustaka Belajar.

Soekarno. 2003. Buku Penuntun Membuat Pola Busana Tingkat Dasar. Jakarta : PT. BPK Gunung Mulia.

Sudjana. 2002. Metode Penelitian. Bandung : Tarsito.

Sugiyono. 2011. Metode Penelitian Kuantitatif, Kualitatif, $R$ \& D. Bandung : CV. Alfabeta.

Wancik. 2005. Pelajaran Menjahit Pakaian Pria Buku III, Bina Busana. Jakarta : Gramedia Pustaka Umum.

Windy. 2009. Konstruksi Busana Wanita. Bandung : Gunung Mulia.

Wirakusumah, Emma, S. 2007. Cara Aman dan Efektif Menurunkan Berat Badan Ideal. Jakarta : Dian Rakyat.

Widiarti. 2006. Panduan Celana Panjang. Jakarta : Reka Busana Muslim. 